\title{
Planned Versus On-Demand Relaparotomy Strategy in Initial Surgery for Non-occlusive Mesenteric Ischemia
}

\author{
Akira Endo ${ }^{1}$ (1) $\cdot$ Fumitaka Saida $^{2} \cdot$ Yuzuru Mochida $^{3} \cdot$ Shiei Kim $^{4} \cdot$ Yasuhiro Otomo $^{1} \cdot$ Daisuke Nemoto $^{5}$. \\ Hisahiro Matsubara ${ }^{6} \cdot$ Shigeru Yamagishi $^{7} \cdot$ Yoshinori Murao $^{8} \cdot$ Kazuki Mashiko $^{9} \cdot$ Satoshi Hirano $^{10}$. \\ Kentaro Yoshikawa ${ }^{11} \cdot$ Toshiki Sera $^{12} \cdot$ Mototaka Inaba $^{13} \cdot$ Hiroyuki Koami ${ }^{14}$ - Makoto Kobayashi ${ }^{15}$. \\ Kiyoshi Murata ${ }^{16} \cdot$ Tomohisa Shoko $^{2} \cdot$ Noriaki Takiguchi $^{17}$
}

Received: 11 March 2020 / Accepted: 6 September 2020 / Published online: 15 September 2020

(C) 2020 The Society for Surgery of the Alimentary Tract

\begin{abstract}
Background There has been insufficient evidence regarding a treatment strategy for patients with non-occlusive mesenteric ischemia (NOMI) due to the lack of large-scale studies. We aimed to evaluate the clinical benefit of strategic planned relaparotomy in patients with NOMI using detailed perioperative information.

Methods We conducted a multicenter retrospective cohort study that included NOMI patients who underwent laparotomy. Inhospital mortality, 28-day mortality, incidence of total adverse events, ventilator-free days, and intensive care unit (ICU)-free days were compared between groups experiencing the planned and on-demand relaparotomy strategies. Analyses were performed using a multivariate mixed effects model and a propensity score matching model after adjusting for pre-operative, intraoperative, and hospital-related confounders.

Results A total of 181 patients from 17 hospitals were included, of whom 107 (59.1\%) were treated using the planned relaparotomy strategy. The multivariate mixed effects regression model indicated no significant differences for in-hospital mortality (61 patients [57.0\%] in the planned relaparotomy group vs. 28 patients [37.8\%] in the on-demand relaparotomy group; adjusted odds ratio [95\% confidence interval] $=1.94[0.78-4.80]$ ), as well as in 28-day mortality, adverse events, and ICU-free days. Significant reduction in ventilator-free days was observed in the planned relaparotomy group. Propensity score matching analysis of 61 matched pairs with comparable patient severity did not show superiority of the planned relaparotomy strategy. Conclusions The planned relaparotomy strategy, compared with on-demand relaparotomy strategy, did not show clinical benefits after the initial surgery of patients with NOMI. Further studies estimating potential subpopulations who may benefit from this strategy are required.
\end{abstract}

Keywords Acute care surgery $\cdot$ Acute mesenteric ischemia $\cdot$ Open abdominal management $\cdot$ Surgery $\cdot$ Critical care

\section{Introduction}

Non-occlusive mesenteric ischemia (NOMI) is generally defined by mesenteric ischemia without occlusion of the mesenteric arteries. ${ }^{1}$ It often occurs in critically ill patients with

Electronic supplementary material The online version of this article (https://doi.org/10.1007/s11605-020-04792-3) contains supplementary material, which is available to authorized users.

Akira Endo

eraeaccm@tmd.ac.jp

Extended author information available on the last page of the article severe circulatory failure and accounts for the major cause of death in intensive care units (ICUs). Although NOMI was first reported by Ende in $1959,{ }^{2}$ a large-scale study has not yet been conducted because of the low prevalence of the conditionreported to represent $5-15 \%$ of all-cause acute mesenteric ischemia (AMI). ${ }^{3}$ Therefore, a therapeutic strategy supported by sufficient evidence has not been established, although the mortality rate of NOMI is reported to be up to $70 \%{ }^{4}$

Strategic staged laparotomy was originally proposed for severe trauma cases, ${ }^{5}$ and it has since become common in non-trauma patients as well. ${ }^{6}$ In cases with irreversible ischemic changes in the bowel, resection of the necrotic bowel can be the last treatment option to salvage the patients; however, because of the NOMI-specific characteristics of progressive, 
segmental, and interrupted ischemic lesions, ${ }^{7,8}$ it is often difficult to definitively detect the irreversible ischemic region in order to resect the bowel sufficiently in the appropriate region. In such cases, second-look surgery has been proposed as a strategic option. ${ }^{9,10}$ Actually, in the case of severe neonatal necrotizing enterocolitis, it was reported that ischemic changes of the bowel do not always require surgical resection and can be improved by stabilization of general conditions, and the usefulness of second-look surgery was suggested, although the pathology is not identical. ${ }^{11,12}$

Accordingly, it could be hypothesized that patients with NOMI represent one of the most suitable candidates to benefit from the planned relaparotomy strategy. This retrospective multicenter observational study aimed to compare two different surgical strategies, the planned relaparotomy strategy and the on-demand relaparotomy strategy, with regard to mortality of patients after the initial surgery for NOMI.

\section{Materials and Methods}

\section{Study Design and Settings}

This was a multicenter retrospective cohort study analyzing data of patients with NOMI in 17 Japanese hospitals, which compared the treatment strategies, planned relaparotomy strategy or on-demand relaparotomy strategy. All participating hospitals were teaching hospitals, and all except one were government-approved tertiary emergency hospitals. The list of participating facilities is presented in Supplemental Table 1 . The study was approved by the institutional ethics committees of each participating hospital.

\section{Study Population}

Data of consecutive patients who underwent laparotomy for NOMI in the participating hospitals between January 2010 and December 2016 were analyzed. NOMI was defined as mesenteric ischemia without occlusion of the mesenteric arteries. Mesenteric ischemia was diagnosed by intra-operative findings, and presence or absence of artery occlusion was assessed by radiological and intra-operative findings. Patients younger than 18 years, who were pregnant, who had do-not-resuscitate orders, or who refused to participate by opting-out were excluded at the stage of data collection.

\section{Data Collection and Outcome Measures}

We retrospectively collected data from medical, surgical, and anesthesia records, including images of surgical specimens, regarding patient baseline characteristics, perioperative information including treatment strategy (i.e., planned relaparotomy strategy or on-demand relaparotomy strategy), patient severity, hospital information, and the patient outcomes described below. The indications for the relaparotomy in patients who were treated with on-demand relaparotomy strategy were also collected. Details in collected variables are described in Supplemental Method.

The primary outcome was defined as in-hospital mortality. Secondary outcomes were 28-day mortality, composite of adverse events (in-hospital mortality, pneumonia, acute kidney injury (AKI), thrombosis, hemorrhage, sepsis, anastomotic leakage, ileus, and entero-atmospheric fistulae), ventilatorfree days at 28 days, and ICU-free days at 28 days. ${ }^{13}$

\section{Statistical Analysis}

Considering the low prevalence of NOMI, the missing values were complemented using the method of multiple imputation by chained equations ${ }^{14}$ in order to make maximum use of available data. In all, 15 datasets with 10 iterations were produced. Descriptive statistics displayed after pooling of all the imputed datasets into one dataset. Predictive statistics displayed after integration across the imputed datasets based on Rubin's rule. ${ }^{15}$ In univariate analysis, continuous variables were compared using a Student's $t$ test, and categorical variables were compared using the $\chi 2$ test.

As the primary analysis, the effect of the planned relaparotomy strategy was evaluated using a mixed effects regression model or a linear-mixed regression model, as appropriate, which could simultaneously adjust for patientlevel confounding factors and hospital-level clustering. ${ }^{16}$ Based on a clinical perspective, simultaneously considering the issue of multicollinearity and the number of outcomes, the following fixed-effect variables were selected for case mix adjustment: age, sex, Charlson comorbidity index, ${ }^{17}$ body mass index, serum lactate value before surgery, Sequential Organ Failure Assessment (SOFA) score before surgery, length of necrotic bowel, and the dose of vasopressors summarized by vasoactive inotropic score (VIS) ${ }^{18,19}$ at the end of initial surgery. The issue of multicollinearity was evaluated by the variance inflation factor, and a value of less than 2 was considered acceptable.

Considering the heterogeneity of the study population, we performed propensity score matching analysis, ${ }^{20}$ as the sensitivity analysis, to extract a population with a similar likelihood of receiving the planned relaparotomy or the on-demand relaparotomy strategy. The propensity score for predicting the planned relaparotomy strategy was calculated by a logistic regression model with adjustment for APACHE II score before surgery, fluid balance during the initial surgery, and the surgeon experience, in addition to the variables used in the aforementioned mixed-effect regression models. Propensity score matching extracted 1:1 matched pair from the planned relaparotomy group (planned group) and on-demand relaparotomy group (on-demand group). The balance of 
matching between the two groups was assessed by the absolute standardized mean difference of all variables, in which values lower than 0.1 were regarded as acceptable. Intergroup comparison of the outcomes with propensity score-matched subjects was performed using a chi-square test.

Furthermore, the primary analysis was also performed for the naive dataset, not the multiply imputed data, as a validation of multiple imputation method, in which variables mentioned above were used for severity adjustment.

All statistical analyses were performed using $\mathrm{R}$ software (version 3.5.1; R Foundation for Statistical Computing, Vienna, Austria). The level of significance was defined as $p<0.05$.

\section{Results}

\section{Study Population}

A total of 181 NOMI patients were analyzed. Patient characteristics of the naïve data, including the proportion of missing data in each variable, are summarized in Supplemental Table 2 . For approximately $34.8 \%$ and $23.8 \%$ cases, data on Acute Physiology and Chronic Health Evaluation (APACHE) score and SOFA score, respectively, were lacking due to the absence of data used for calculation of these scores. Data for VIS were missing for $18.8 \%$ of cases. The proportions of missing data for other variables were less than approximately $10 \%$. The missing data for these variables were complemented using a multiple imputation method.

Patients' demographic data and their pre-operative status in the multiply imputed cohort are summarized in Table 1. Median age was 77 years, and 110 patients $(60.8 \%)$ were male. In the initial surgery, 107 patients $(59.1 \%)$ were treated with the planned relaparotomy strategy. APACHE II scores were higher in patients treated with the planned relaparotomy strategy compared to those treated with the on-demand relaparotomy strategy $[25(20,32)$ in the planned group and $21(17,29)$ in the on-demand group], as well as SOFA scores $[9(4,13)$ in the planned group and $6(4,10)$ in the on-demand group] and lactate levels $[5.4(2.5,8.7)$ in the planned group and $3.1(1.7,6.1)$ in the on-demand group]. Surgical information for the multiply imputed cohort is summarized in Table 2 . In the planned group, 99 (92.5\%) were treated with OAM; the remaining 8 patients did not undergo OAM, and their abdominal walls were temporally closed. Although the median value of the length of necrotic bowel was similar for both groups, parameters during initial surgery, such as urine volume $[40 \mathrm{~mL}(0,190)$ in the planned group and $130 \mathrm{~mL}(0,310)$ in the on-demand group] and the VIS at the end of an initial surgery $[17.8(5.3,42.9)$ in the planned group and $7.5(0.0$, 21.4 ) in the on-demand group], also suggested that more severe cases were likely to be treated with planned relaparotomy strategy. Shorter operation times were observed in the planned group [98 $\min (70,150)$ in the planned group and $151 \mathrm{~min}$ $(120,197)$ in the on-demand group]. Additional bowel resection, in which the bowel resection in short length for only the purpose of anastomotic procedure was not counted, was performed in 47 patients $(43.9 \%)$ of the planned group and 3 patients $(4.1 \%)$ of the on-demand group. Regarding the patients who received additional bowel resection in the ondemand relaparotomy group, the indications for relaparotomy were sustained deteriorated general condition, anastomotic leakage, and remnant abscess.

\section{Primary Analysis}

The number of outcomes and the results of univariate analysis are summarized in Table 3. The rates of in-hospital mortality, 28-day mortality, and total adverse events were significantly higher, while the ventilator-free days and ICU-free days were significantly fewer in the planned group. In-hospital mortality was observed in 89 patients (49.2\%) among the entire study population: 61 patients $(57.0 \%)$ in the planned group and 28 patients $(37.8 \%)$ in the on-demand group. Total adverse events were observed in 123 patients $(68.0 \%)$ of the entire study population [80 patients $(74.8 \%)$ in the planned group and 43 patients $(58.1 \%)$ in the on-demand group]; of those, $\mathrm{AKI}$ and sepsis were significantly frequent in the planned group. The ventilator-free days was 0 days $(0,16)$ in the planned group and 17.5 days $(0,25)$ in the on-demand group, and the ICU-free days was 0 days $(0,19)$ in the planned group and 15 days $(0,24)$ in the on-demand group.

All of the variance inflation factors of the variables that were incorporated into the model were less than 2 , which eliminated the issue of multicollinearity in the regression model. The results of the multivariate mixed effects model are summarized in Table 4. After adjusting for potential confounders in the mixed effects regression models, significant differences observed in the univariate comparisons disappeared except for ventilator-free days [adjusted odds ratio (AOR) for in-hospital mortality $(95 \% \mathrm{CI})=1.94(0.78$ 4.81); AOR for 28-day mortality $(95 \% \mathrm{CI})=1.74(0.63$ 4.82); AOR for total adverse events $(95 \% \mathrm{CI})=1.39(0.45$ 4.32); adjusted difference for ventilator-free days $(95 \% \mathrm{CI})=$ $-3.6(-6.8--0.3)$; and adjusted difference for ICU-free days $(95 \% \mathrm{CI})=-2.3(-5.5-0.9)]$.

\section{Sensitivity Analyses}

Through the matching process, 61 propensity score-matched pairs were generated. Patients who had extremely high probability for the implementation of on-demand relaparotomy strategys or planned relaparotomy strategy, respectively, were excluded via the process (Supplemental Figure 1). The standardized mean differences of the variables used in the 
Table 1 Demographic and pre-operative status of the study population (multiply imputed cohort)

\begin{tabular}{|c|c|c|c|}
\hline Variables & $\begin{array}{l}\text { Planned } \\
\text { relaparotomy }\end{array}$ & $\begin{array}{l}\text { On-demand } \\
\text { relaparotomy }\end{array}$ & $\begin{array}{l}P \\
\text { value }\end{array}$ \\
\hline Number of subjects, $n$ & 107 & 74 & - \\
\hline \multicolumn{4}{|l|}{ Baseline characteristics } \\
\hline Age, years & $78[67,84]$ & $76[64,84]$ & 0.576 \\
\hline Sex, male & $66(61.7)$ & $44(59.5)$ & 0.764 \\
\hline Height, $\mathrm{cm}$ & $160[150,165]$ & $156[150,165]$ & 0.627 \\
\hline Weight, kg & $51.0[43.0,59.7]$ & $49.7[43.0,58.6]$ & 0.168 \\
\hline Body mass index & $20.5[18.1,23.5]$ & $20.5[18.1,22.8]$ & 0.289 \\
\hline Charlson comorbidity index & $2[1,4]$ & $3[2,4]$ & 0.086 \\
\hline \multicolumn{4}{|l|}{ Pre-operative status } \\
\hline Glasgow coma scale & $13[4,15]$ & $14[10,15]$ & 0.103 \\
\hline Systolic blood pressure, $\mathrm{mmHg}$ & $91[72,115]$ & $97[77,116]$ & 0.314 \\
\hline Diastolic blood pressure, $\mathrm{mmHg}$ & $51[40,67]$ & $51[42,65]$ & 0.762 \\
\hline Respiratory rate, breath per min & $25[19,32]$ & $25[19,30]$ & 0.529 \\
\hline Heart rate, beat per min & $101[82,123]$ & $97[77,114]$ & 0.051 \\
\hline Body temperature, ${ }^{\circ} \mathrm{C}$ & $36.5[35.6,37.2]$ & $36.8[35.8,37.6]$ & 0.133 \\
\hline $\mathrm{PaO}_{2}, \mathrm{mmHg}$ & $119.7[88.3,183.0]$ & $94.9[76.7,138.0]$ & 0.042 \\
\hline $\mathrm{PaCO}_{2}, \mathrm{mmHg}$ & $32.6[26.5,41.6]$ & $33.8[29.3,40.8]$ & 0.673 \\
\hline $\mathrm{FiO}_{2}$ & $0.50[0.21,1.00]$ & $0.40[0.21,0.60]$ & 0.013 \\
\hline Arterial $\mathrm{pH}$ & $7.35[7.25,7.41]$ & $7.36[7.30,7.43]$ & 0.275 \\
\hline Venous $\mathrm{HCO}_{3}, \mathrm{mmol} / \mathrm{L}$ & $17.0[12.9,22.4]$ & $20.0[15.9,23.2]$ & 0.107 \\
\hline White blood cell counts, $10^{3} / \mu \mathrm{L}$ & $9.5[5.5,15.2]$ & $10.4[6.4,17.1]$ & 0.879 \\
\hline Platelet counts, $10^{4} / \mu \mathrm{L}$ & $14.9[8.2,21.2]$ & $15.3[9.8,20.5]$ & 0.498 \\
\hline Hematocrit, $\%$ & $34.4[29.6,40.5]$ & $33.2[27.8,39.3]$ & 0.308 \\
\hline Total bilirubin, $\mathrm{mg} / \mathrm{dL}$ & $0.7[0.5,1.2]$ & $0.9[0.5,1.4]$ & 0.966 \\
\hline Creatinine, mg/dL & $1.9[1.2,3.5]$ & $1.7[1.0,3.2]$ & 0.532 \\
\hline $\mathrm{Na}, \mathrm{mEq} / \mathrm{L}$ & $139[136,142]$ & $137[133,140]$ & 0.022 \\
\hline $\mathrm{K}, \mathrm{mEq} / \mathrm{L}$ & $4.2[3.7,5.2]$ & $4.3[3.9,4.7]$ & 0.407 \\
\hline Lactate, $\mathrm{mmol} / \mathrm{L}$ & $5.4[2.5,8.7]$ & $3.1[1.7,6.1]$ & 0.056 \\
\hline Dose of vasopressors & & & 0.001 \\
\hline None & $52(48.6)$ & $48(64.9)$ & \\
\hline Dopamine $\leq 5 \mu \mathrm{g} / \mathrm{kg} / \mathrm{min}$ or dobutamine (any dose) & $1(0.9)$ & $5(6.8)$ & \\
\hline $\begin{array}{l}\text { Dopamine }>5 \mu \mathrm{g} / \mathrm{kg} / \mathrm{min} \text { or epinephrine } \leq 0.1 \mu \mathrm{g} / \mathrm{kg} / \mathrm{min} \text { or norepinephrine } \\
\leq 0.1 \mu \mathrm{g} / \mathrm{kg} / \mathrm{min}\end{array}$ & $12(11.2)$ & $11(14.9)$ & \\
\hline $\begin{array}{l}\text { Dopamine }>15 \mu \mathrm{g} / \mathrm{kg} / \mathrm{min} \text { or epinephrine }>0.1 \mu \mathrm{g} / \mathrm{kg} / \mathrm{min} \text { or norepinephrine } \\
>0.1 \mu \mathrm{g} / \mathrm{kg} / \mathrm{min}\end{array}$ & $42(39.3)$ & $10(13.5)$ & \\
\hline APACHE II score & $25[20,32]$ & $21[17,29]$ & 0.013 \\
\hline SOFA score & $9[4,13]$ & $6[4,10]$ & 0.052 \\
\hline
\end{tabular}

Continual variables are expressed as median [25th and 75th percentiles]; categorical variables are expressed as number (\%).APACHE Acute Physiology and Chronic Health Evaluation, SOFA Sequential Organ Failure Assessment

propensity score estimation indicated well-balanced matching (Table 5). The results of the propensity score matching analysis are shown in Table 6. The superiority of planned relaparotomy was also not observed in this model.

The results of the mixed-effect regression analysis for the naïve data are summarized in Supplemental Table 3. The results were similar to the primary analysis using multiply imputed data.

\section{Discussion}

Although NOMI is a serious disease with a high mortality rate, an evidence-based therapeutic strategy has not yet been established due to the lack of large-scale studies. A randomized controlled trial or a prospective observational study under the strict indication is ideal design to compare two different therapeutic strategies (planned relaparotomy strategy 
Table 2 Surgical information of the study population (multiply imputed cohort)

\begin{tabular}{|c|c|c|c|}
\hline Variables & Planned relaparotomy & On-demand relaparotomy & $P$ value \\
\hline \multicolumn{4}{|l|}{ Information during initial surgery } \\
\hline Length of ischemic bowel, cm & $100[45,160]$ & $100[50,200]$ & 0201 \\
\hline Hemorrhage volume, $\mathrm{mL}$ & $205[50,861]$ & $269[60,997]$ & 0.277 \\
\hline Urine, $\mathrm{mL}$ & $40[0,190]$ & $130[0,310]$ & 0459 \\
\hline Administered crystalloid, $\mathrm{mL}$ & $1650[800,2700]$ & $1400[700,2100]$ & 0.151 \\
\hline Administered colloid, mL & $250[0,900]$ & $500[250,1000]$ & 0.191 \\
\hline \multicolumn{4}{|l|}{ Administered transfusion, unit* } \\
\hline Red blood cells & $2[0,6]$ & $4[0,4]$ & 0.358 \\
\hline Plasma & $4[0,6]$ & $2[0,6]$ & 0.095 \\
\hline Platelets & $0[0,0]$ & $0[0,0]$ & 0.026 \\
\hline \multicolumn{4}{|l|}{ Dose of vasopressors at the end of the initial surgery } \\
\hline Norepinephrine, $\mathrm{mg} / \mathrm{h}$ & $0.48[0.06,1.00]$ & $0.10[0.00,0.44]$ & $<0.001$ \\
\hline Dopamine, mg/h & $0[0,0]$ & $0[0,9.00]$ & 0.217 \\
\hline Epinephrine, mg/h & $0[0,0]$ & $0[0,0]$ & 0.884 \\
\hline Dobutamine, $\mathrm{mg} / \mathrm{h}$ & $0[0,0]$ & $0[0,0]$ & 0.864 \\
\hline Vasopressin, unit/h & $0[0,0]$ & $0[0,0]$ & 0.265 \\
\hline Vasoactive inotropic score & $17.8[5.3,42.9]$ & $7.5[0.0,21.4]$ & $<0.001$ \\
\hline Operation time, $\min$ & $98[70,150]$ & $151[120,197]$ & $<0.001$ \\
\hline \multicolumn{4}{|l|}{ Additional treatments } \\
\hline Endovascular therapy & & & 0.155 \\
\hline $\begin{array}{l}\text { None } \\
\text { Pre-surgery }\end{array}$ & $\begin{array}{l}102(95.3) \\
3(2.8)\end{array}$ & $\begin{array}{l}70(94.6) \\
0(0)\end{array}$ & \\
\hline Post-surgery & $2(1.9)$ & $4(5.4)$ & \\
\hline Vasodilator use & & & 0.068 \\
\hline $\begin{array}{l}\text { None } \\
\text { Pre-surgery }\end{array}$ & $\begin{array}{l}97(90.7) \\
3(2.8)\end{array}$ & $\begin{array}{l}57(77.0) \\
6(8.1)\end{array}$ & \\
\hline During surgery & $0(0)$ & $1(1.4)$ & \\
\hline Post-surgery & $7(6.5)$ & $10(13.5)$ & \\
\hline Heparin use & & & 0.661 \\
\hline None & $97(90.7)$ & $67(90.5)$ & \\
\hline Pre-surgery & $4(3.7)$ & $2(2.7)$ & \\
\hline During surgery & $0(0)$ & $1(1.4)$ & \\
\hline Post-surgery & $6(5.6)$ & $4(5.4)$ & \\
\hline Open abdominal management & $99(92.5)$ & $0(0)$ & $<0.001$ \\
\hline Additional bowel resection & $47(43.9)$ & $3(4.1)$ & $<0.001$ \\
\hline \multicolumn{4}{|l|}{ Treating hospital-related variables } \\
\hline Mean number of surgeons per hospital during study period & $12[5,13]$ & $12[5,20]$ & $<0.001$ \\
\hline Mean annual number of surgeries under general anesthesia during study period & $230[150,371]$ & $371[371,850]$ & $<0.001$ \\
\hline Surgeon experience, cases/year & $25.3[14.5,55.8]$ & $55.0[15.3,74.1]$ & $<0.001$ \\
\hline
\end{tabular}

Continual variables are expressed as median [25th and 75th percentiles]; categorical variables are expressed as number (\%)

*One unit of transfusion was prepared from $200 \mathrm{~mL}$ of whole blood in Japan

and on-demand relaparotomy strategy) in NOMI; however, those would be impractical owing to the rarity of the disease. Therefore, in the present study, we conducted a multicenter retrospective cohort study with adjustment of detailed perioperative variables. The result provided detailed information on baseline characteristics, perioperative conditions, and strategy of initial surgeries in a larger number of NOMI patients compared with previous literatures. To the best of our knowledge, this is the first well-designed retrospective cohort study that evaluated the efficacy of the planned relaparotomy strategy in patients with NOMI. However, the clinical benefits of the planned relaparotomy strategy were 
Table 3 Results of the univariate analysis for the study outcomes

\begin{tabular}{lccr}
\hline Outcome measurements & $\begin{array}{l}\text { Planned relaparotomy } \\
(n=107)\end{array}$ & $\begin{array}{l}\text { On-demand relaparotomy } \\
(n=74)\end{array}$ & $P$ values \\
\hline Primary outcome & & $28(37.8)$ & 0.013 \\
In-hospital mortality & $61(57.0)$ & $19(25.7)$ & 0.014 \\
Secondary outcomes & $47(43.9)$ & $43(58.1)$ & 0.020 \\
28-day mortality & $80(74.8)$ & $28(37.8)$ & 0.013 \\
Total adverse events & $61(57.0)$ & $13(17.6)$ & 0.896 \\
In-hospital mortality & $18(16.8)$ & $10(13.5)$ & 0.009 \\
Pneumonia & $33(30.8)$ & $4(5.4)$ & 0.953 \\
Acute kidney injury & $6(5.6)$ & $4(5.4)$ & 0.754 \\
Thrombosis & $7(6.5)$ & $20(27.0)$ & 0.004 \\
Hemorrhage & $52(48.6)$ & $3(4.1)$ & 0.074 \\
Sepsis & $13(12.1)$ & $7(9.5)$ & 0.127 \\
Anastomotic leakage & $4(3.7)$ & $1(1.4)$ & 0.357 \\
Ileus & $4(3.7)$ & $17.5[0,25]$ & $<0.001$ \\
Entero-atmospheric & $0[0,16]$ & $15[0,24]$ & 0.002 \\
$\quad$ fistulae & $0[0,19]$ & & \\
Ventilator-free days, days & ICU-free days, days & &
\end{tabular}

Continual variables are expressed as median [25th and 75 th percentiles]; categorical variables are expressed as number (\%). ICU intensive care unit not observed. Patients with deteriorated perioperative conditions were likely to be chosen for the strategy of planned relaparotomy rather than on-demand relaparotomy, suggesting that the strategic decision was made according to the patient's condition in some cases. Considering this potential heterogeneity in patients, in this study, we tried to minimize the bias by using propensity score matching analysis to compare patients who had a similar likelihood of undergoing the planned relaparotomy or the on-demand relaparotomy. However, although we made the best effort to control potential biases, completely overcoming the difference was impossible due to the possibility of unmeasured confounding factors, such as operative findings that could not be evaluated quantitatively (e.g., the extent of bowel edema).
Damage control strategy was originally proposed for critically injured trauma patients ${ }^{5}$ and was principally based on the concept of staged surgery. ${ }^{21}$ The use of damage control strategies has spread to emergency general surgery, ${ }^{22,23}$ and recent guidelines recommend that such strategies could be used for patients with AMI, including NOMI, ${ }^{10}$ because it is often difficult to sufficiently identify ischemic lesions during initial surgery. Ward et al. ${ }^{24}$ reported that half of NOMI patients who underwent second-look operations required additional bowel resection. Therefore, planned relaparotomy based on the damage control strategy appears to be a reasonable approach to determine the appropriate region to be resected and to avoid high-risk anastomosis under deteriorated health conditions. On the other hand, it should be noted that several previous

Table 4 Results of multivariate mixed effects regression analysis (primary analysis)

\begin{tabular}{|c|c|c|c|c|c|}
\hline Outcomes & $\begin{array}{l}\text { Crude odds ratio } \\
{[95 \% \mathrm{CI}]}\end{array}$ & $\begin{array}{l}\text { Crude difference } \\
{[95 \% \mathrm{CI}]}\end{array}$ & $\begin{array}{l}\text { Adjusted odds ratio } \\
{[95 \% \mathrm{CI}]}\end{array}$ & $\begin{array}{l}\text { Adjusted difference } \\
{[95 \% \mathrm{CI}]}\end{array}$ & $\begin{array}{l}\text { Adjusted } \\
p \text { value }\end{array}$ \\
\hline \multicolumn{6}{|l|}{ Primary outcome } \\
\hline In-hospital mortality & $2.18(1.19-3.99)$ & - & $1.94(0.78-4.80)$ & - & 0.156 \\
\hline \multicolumn{6}{|l|}{ Secondary outcomes } \\
\hline 28-day mortality & $2.27(1.19-4.33)$ & - & $1.74(0.63-4.82)$ & - & 0.291 \\
\hline Total adverse events & $2.14(1.13-4.03)$ & - & $1.39(0.45-4.32)$ & - & 0.568 \\
\hline Ventilator-free days & - & $-6.7(-9.7--3.6)$ & - & $-3.6(-6.8-0.3)$ & 0.034 \\
\hline ICU-free days & - & $-5.2(-8.4--2.0)$ & - & $-2.3(-5.5-0.9)$ & 0.161 \\
\hline
\end{tabular}

$C I$ confidence interval, ICU intensive care unit. The level of significance was defined as $p<0.05$ 
Table 5 Characteristics of the patients before and after propensity score matching

\begin{tabular}{|c|c|c|c|c|c|c|}
\hline \multirow[t]{2}{*}{ Variables } & \multicolumn{3}{|l|}{ Unmatched cohort } & \multicolumn{3}{|l|}{ Matched cohort } \\
\hline & $\begin{array}{l}\text { Planned } \\
\text { relaparotomy }\end{array}$ & $\begin{array}{l}\text { On-demand } \\
\text { relaparotomy }\end{array}$ & ASMD & $\begin{array}{l}\text { Planned } \\
\text { relaparotomy }\end{array}$ & $\begin{array}{l}\text { On-demand } \\
\text { relaparotomy }\end{array}$ & ASMD \\
\hline Number of subjects, $n$ & 107 & 74 & - & 61 & 61 & - \\
\hline \multicolumn{7}{|l|}{ Baseline characteristics } \\
\hline Age, years & $78[67,84]$ & $76[64,84]$ & 0.08 & $76[70,83]$ & $77[66,84]$ & 0.06 \\
\hline Sex, male & $66(61.7)$ & $44(59.5)$ & 0.05 & $39(61.9)$ & $40(63.5)$ & 0.033 \\
\hline Body mass index & $20.5[18.1,23.5]$ & $20.5[18.1,22.8]$ & 0.18 & $20.5[18.8,23.2]$ & $20.7[18.1,22.8]$ & 0.00 \\
\hline Charlson comorbidity index & $2[1,4]$ & $3[2,4]$ & 0.26 & $3[2,4]$ & $3[2,4]$ & 0.03 \\
\hline \multicolumn{7}{|l|}{ Pre-operative status } \\
\hline APACHE II score & $25[20,32]$ & $21[17,29]$ & 0.39 & $24[18,33]$ & $22[19,30]$ & 0.05 \\
\hline SOFA score & $9[4,13]$ & $6[4,10]$ & 0.30 & $8[4,13]$ & $7[5,10]$ & 0.09 \\
\hline \multicolumn{7}{|l|}{ Information during initial surgery } \\
\hline Length of ischemic bowel, $\mathrm{cm}$ & $100[45,160]$ & $100[50,200]$ & 0.24 & $120[60,200]$ & $100[40,180]$ & 0.00 \\
\hline Fluid balance, $\mathrm{mL}$ & $2090[1400,3552]$ & $1980[1340,2955]$ & 0.17 & $2024[1200,3101]$ & $2097[1480,3050]$ & 0.05 \\
\hline Vasoactive inotropic score & $17.8[5.3,42.9]$ & $7.5[0.0,21.4]$ & 0.63 & $10.3[1.5,22.4]$ & $11.7[2.8,22.8]$ & 0.10 \\
\hline \multicolumn{7}{|l|}{ Treating hospital-related variables } \\
\hline $\begin{array}{l}\text { Surgeon's experience, } \\
\text { cases/year }\end{array}$ & $25.3[14.5,55.8]$ & $55.0[15.3,74.1]$ & 0.51 & $35.7[15.3,74.1]$ & $55.0[14.5,74.1]$ & 0.02 \\
\hline
\end{tabular}

Continuous variables are expressed as median [25th and 75th percentiles]; categorical variables are expressed as number (\%).ASMD absolute standardized mean difference, APACHE Acute Physiology and Chronic Health Evaluation, SOFA Sequential Organ Failure Assessment

publications have raised concerns regarding the overuse of damage control laparotomy for trauma ${ }^{25}$ and non-trauma patients. ${ }^{26}$ The results of the present study could be interpreted as demonstrating that the risks of indiscriminate use of planned relaparotomy strategy outweigh the benefits in some cases. In fact, approximately $56 \%$ of the patients in the planned group did not receive additional bowel resection. This suggests that while some patients may benefit from the

Table 6 Study outcomes in the propensity score-matched population (sensitivity analysis)

\begin{tabular}{|c|c|c|c|c|c|}
\hline Outcome measurements & $\begin{array}{l}\text { Planned relaparotomy } \\
(n=61)\end{array}$ & $\begin{array}{l}\text { On-demand relaparotomy } \\
(n=61)\end{array}$ & $\begin{array}{l}\text { Odds ratio } \\
(95 \% \mathrm{CI})\end{array}$ & $\begin{array}{l}\text { Difference } \\
(95 \% \mathrm{CI})\end{array}$ & $p$ value \\
\hline \multicolumn{6}{|l|}{ Primary outcome } \\
\hline In-hospital mortality & $32(52.5)$ & $26(42.6)$ & $1.49(0.73-3.03)$ & - & 0.280 \\
\hline \multicolumn{6}{|l|}{ Secondary outcomes } \\
\hline 28-day mortality & $22(36.1)$ & $18(29.5)$ & $1.35(0.63-2.88)$ & - & 0.443 \\
\hline Total adverse events & $40(65.6)$ & $37(60.7)$ & $1.24(0.59-2.58)$ & - & 0.575 \\
\hline In-hospital mortality & $32(52.5)$ & $26(42.6)$ & - & - & - \\
\hline Pneumonia & $11(18.0)$ & $12(19.7)$ & - & - & - \\
\hline Acute kidney injury & $15(24.6)$ & $9(14.8)$ & - & - & - \\
\hline Thrombosis & $4(6.6)$ & $2(3.3)$ & - & - & - \\
\hline Hemorrhage & $3(4.9)$ & $1(1.6)$ & - & - & - \\
\hline Sepsis & $26(42.6)$ & $19(31.1)$ & - & - & - \\
\hline Anastomotic leakage & $4(6.6)$ & $3(4.9)$ & - & - & - \\
\hline Ileus & $1(1.6)$ & $7(11.5)$ & - & - & - \\
\hline Entero-atmospheric fistulae & $2(3.3)$ & $1(1.6)$ & - & - & - \\
\hline Ventilator-free days & $0[0,19.0]$ & $16[0,24]$ & - & $-4.1(-7.9-0.3)$ & 0.036 \\
\hline ICU-free days & $0[0,21]$ & $6[0,23]$ & - & $-2.3(-6.3-1.6)$ & 0.253 \\
\hline
\end{tabular}

Continuous variables are expressed as median [25th and 75th percentiles]; categorical variables are expressed as number (\%). CI confidence interval, ICU intensive care unit. The level of significance was defined as $p<0.05$ 
planned relaparotomy, it could cause others to incur unnecessary risk, at least from a retrospective view. OAM was said to be one of the risk factors for anastomotic leakage ${ }^{27}$ and entero-atmospheric fistulae. ${ }^{28}$ Although these rates of occurrence were relatively greater in the planned group (anastomotic leakage: $12.1 \%$ vs. $4.1 \%$ and entero-atmospheric fistulae: $3.7 \%$ vs. $1.4 \%$, respectively), causal inference for each adverse event could not be evaluated due to the low prevalence.

In this study population, 47 patients (44\%) in the planned group received additional bowel resection. These patients might be informative because they could potentially inform the best strategic approaches. In some patients of the planned group, surgeons might have resected only obviously non-viable bowel segment in the initial surgery, leaving the region that was difficult to judge whether or not the ischemic change was irreversible, and the region which was revealed to be irreversible ischemia in the secondary surgery might have been resected additionally. In other patients, surgeons might have performed additional resection of almost all the suspected ischemic bowel segments for only the purpose of safe anastomosis in the secondary surgery regardless of whether the ischemic change of the additionally resected regions was irreversible or not. In the former situation, bowel segment with irreversible ischemia was left in the abdominal cavity in initial surgery; those patients might have been more frequent in the planned group, compared with on-demand group, because surgeons usually do not leave suspected ischemic bowel segment in patients who are intended to close abdomen owing to safety concerns. This could be one of the reasons for the relatively high mortality rate in the planned group. In the latter situation, the concern of unnecessary bowel resection was raised. Although it was not considered to be a reason for relatively worse survival outcome observed in the planned group, it could be one of the explanations why additional resection was more frequent. The ideal treatment for NOMI can be achieved by avoiding unnecessary bowel resection while simultaneously controlling the risk of physiologic deterioration caused by necrotic bowels. Recent improvements in the management of NOMI, including examination modalities and additional treatment options, might affect therapeutic strategy by avoiding the overuse of planned relaparotomy strategy and unnecessary bowel resection. For example, intra-operative use of indocyanine green fluorescence has been reported to precisely detect ischemic lesions. ${ }^{29,30}$ Some patients were reported to be well managed through endovascular therapy. ${ }^{31,32}$ These recent advances in clinical practice might serve to optimize the use of planned relaparotomy strategy.

Several limitations should be considered when interpreting the results of this study. Some of the variables had missing values. Subjective factors concerning surgeons' decisionmaking process for the choice of surgical strategies (i.e., planned relaparotomy of on-demand relaparotomy) in each case were unclear. Also, a method to assess the viability of ischemic bowel was not protocolized. Subjective factors, such as visual inspection or palpation of pulse, might have affected the surgeon's decision; collecting these factors was impractical in a retrospective study. Unmeasured variables, such as estimated intra-abdominal pressure at the end of initial surgery, which could influence the outcomes, were not accounted for due to the retrospective nature of the study and limited data availability. Although pre-operative conditions were adjusted using the APACHE II and SOFA scores, the severity of underlying diseases was not evaluated because quantification of these factors is difficult. Limited generalizability would also be a limitation of this study because we analyzed a limited population from 17 Japanese hospitals. Furthermore, the treatment strategy, including technique of temporary abdominal closure (TAC) in the planned group, could not be protocolized; each participating hospital used respective standard operating procedures for TAC such as a self-made vacuum pack closure system or a Bogota bag. However, the main purpose of this study was not to evaluate the effects of different TAC techniques but to compare the two therapeutic strategies in the initial surgery for NOMI. Although this study failed to show any clinical benefit of the planned relaparotomy strategy for NOMI patients, at least in the entire study population, future studies investigating potential subpopulations who benefit from this strategy are required.

\section{Conclusion}

The clinical benefit of the planned re-operation strategy was not observed, at least in the entire study population. Further studies estimating potential subpopulations who would benefit from this strategy would be required.

Acknowledgments The authors thank Motoyasu Yamazaki, Masayuki Yagi, Kosuke Sekiya, Naohisa Masunaga, Shota Nakao, Gaku Ohira, Keita Nakatsutsumi, Mariko Yamamoto, Tomohide Shirosaki, Takahiro Saito, Tadao Kubota, Takao Yamanoue, Masahiko Iseki, Yasuhiro Ueda, Nao Urushibata, Tomohiro Akutsu, and all other collaborators for their invaluable efforts in this study. The authors also would like to thank Editage (https://www.editage.jp) for English language editing.

Compliance with Ethical Standards The study was approved by the institutional ethics committees of each participating hospital.

Conflict of Interest The authors declare that they have no conflicts of interest.

\section{References}

1. Clair DG, Beach JM. Mesenteric ischemia. N Engl J Med 2016;374:959-968.

2. Ende N. Infarction of the bowel in cardiac failure. N Engl J Med 1958;258:879-881. 
3. Acosta S. Epidemiology of mesenteric vascular disease: clinical implications. Semin Vasc Surg 2010;23:4-8.

4. Adaba F, Askari A, Dastur J, Patel A, Gabe SM, Vaizey CJ, Faiz O, Nightingale JM, Warusavitarne J. Mortality after acute primary mesenteric infarction: a systematic review and meta-analysis of observational studies. Colorectal Dis 2015;17:566-577.

5. Rotondo MF, Schwab CW, McGonigal MD, Phillips GR 3rd, Fruchterman TM, Kauder DR, Latenser BA, Angood PA. 'Damage control': an approach for improved survival in exsanguinating penetrating abdominal injury. J Trauma 1993;35:375-382.

6. Coccolini F, Roberts D, Ansaloni L, Ivatury R, Gamberini E, Kluger Y, Moore EE, Coimbra R, Kirkpatrick AW, Pereira BM, Montori G, Ceresoli M, Abu-Zidan FM, Sartelli M, Velmahos G, Fraga GP, Leppaniemi A, Tolonen M, Galante J, Razek T, Maier R, Bala M, Sakakushev B, Khokha V, Malbrain M, Agnoletti V, Peitzman A, Demetrashvili Z, Sugrue M, Di Saverio S, Martzi I, Soreide K, Biffl W, Ferrada P, Parry N, Montravers P, Melotti RM, Salvetti F, Valetti TM, Scalea T, Chiara O, Cimbanassi S, Kashuk JL, Larrea M, Hernandez JAM, Lin HF, Chirica M, Arvieux C, Bing C, Horer T, De Simone B, Masiakos P, Reva V, De Angelis N, Kike K, Balogh ZJ, Fugazzola P, Tomasoni M, Latifi R, Naidoo N, Weber D, Handolin L, Inaba K, Hecker A, Kuo-Ching Y, Ordoñez CA, Rizoli S, Gomes CA, De Moya M, Wani I, Mefire AC, Boffard K, Napolitano L, Catena F. The open abdomen in trauma and non-trauma patients: WSES guidelines. World $\mathrm{J}$ Emerg Surg 2018;13:7.

7. Boley SJ, Sprayregan S, Siegelman SS, Veith FJ. Initial results from an aggressive roentgenological and surgical approach to acute mesenteric ischemia. Surgery 1977;82:848-855.

8. Yukaya T, Saeki H, Taketani K, Ando K, Ida S, Kimura Y, Oki E, Yasuda M, Morita M, Shirabe K, Maehara Y. Clinical outcomes and prognostic factors after surgery for non-occlusive mesenteric ischemia: a multicenter study. J Gastrointest Surg 2014;18:1642-1647.

9. Acosta S, Björck M. Modern treatment of acute mesenteric ischaemia. Br J Surg 2014;101:e100-108.

10. Bala M, Kashuk J, Moore EE, Kluger Y, Biffl W, Gomes CA, BenIshay O, Rubinstein C, Balogh ZJ, Civil I, Coccolini F, Leppaniemi A, Peitzman A, Ansaloni L, Sugrue M, Sartelli M, Di Saverio S, Fraga GP, Catena F. Acute mesenteric ischemia: guidelines of the World Society of Emergency Surgery. World J Emerg Surg 2017;12:38.

11. Pang KK, Chao NS, Wong BP, Leung MW, Liu KK. The clip and drop back technique in the management of multifocal necrotizing enterocolitis: a single centre experience. Eur J Pediatr Surg 2012;22:85-90.

12. Smith J, Thyoka M. What role does laparoscopy play in the diagnosis and immediate treatment of infants with necrotizing enterocolitis? J Laparoendosc Adv Surg Tech A 2013;23:397-401.

13. Young P, Hodgson C, Dulhunty J, Saxena M, Bailey M, Bellomo R, Davies A, Finfer S, Kruger P, Lipman J, Myburgh J, Peake S, Seppelt I, Streat S, Tate R, Webb S; ANZICS Clinical Trials Group. End points for phase II trials in intensive care: recommendations from the Australian and New Zealand Clinical Trials Group consensus panel meeting. Crit Care Resusc 2012;14:211-215.

14. Sterne JA, White IR, Carlin JB, Spratt M, Royston P, Kenward MG, Wood AM, Carpenter JR. Multiple imputation for missing data in epidemiological and clinical research: potential and pitfalls. BMJ 2009;338:b2393.

15. Rubin DB. Multiple Imputation for Nonresponse in Surveys. John Wiley, New York; 1987.

16. Liang KY, Zeger SL. Longitudinal data analysis using generalized linear models. Biometrika 1986;73:13-22.

17. Charlson ME, Pompei P, Ales KL, MacKenzie CR. A new method of classifying prognostic comorbidity in longitudinal studies: development and validation. J Chronic Dis 1987;40:373-383.
18. Gaies MG, Gurney JG, Yen AH, Napoli ML, Gajarski RJ, Ohye RG, Charpie JR, Hirsch JC. Vasoactive-inotropic score as a predictor of morbidity and mortality in infants after cardiopulmonary bypass. Pediatr Crit Care Med 2010;11:234-238.

19. Yamazaki Y, Oba K, Matsui Y, Morimoto Y. Vasoactive-inotropic score as a predictor of morbidity and mortality in adults after cardiac surgery with cardiopulmonary bypass. J Anesth 2018;32:167-173.

20. D'Agostino RB Jr. Propensity score methods for bias reduction in the comparison of a treatment to a non-randomized control group. Stat Med 1998;17:2265-2281.

21. Kouraklis G, Spirakos S, Glinavou A. Damage control surgery: an alternative approach for the management of critically injured patients. Surg Today 2002;32:195-202.

22. Weber DG, Bendinelli C, Balogh ZJ. Damage control surgery for abdominal emergencies. Br J Surg 2014;101:e109-118.

23. Becher RD, Peitzman AB, Sperry JL, Gallaher JR, Neff LP, Sun Y, Miller PR, Chang MC. Damage control operations in non-trauma patients: defining criteria for the staged rapid source control laparotomy in emergency general surgery. World J Emerg Surg 2016;11:10.

24. Ward D, Vernava AM, Kaminski DL, Ure T, Peterson G, Garvin P, Arends TW, Longo WE. Improved outcome by identification of high-risk nonocclusive mesenteric ischemia, aggressive reexploration, and delayed anastomosis. Am J Surg 1995;170: 577-580.

25. Higa G, Friese R, O'Keeffe T, Wynne J, Bowlby P, Ziemba M, Latifi R, Kulvatunyou N, Rhee P. Damage control laparotomy: a vital tool once overused. J Trauma 2010;69:53-59.

26. Kaminsky O, Yampolski I, Aranovich D, Gnessin E, Greif F. Does a second-look operation improve survival in patients with peritonitis due to acute mesenteric ischemia? A five-year retrospective experience. World J Surg 2005;29:645-648.

27. Bruns BR, Morris DS, Zielinski M, Mowery NT, Miller PR, Arnold K, Phelan HA, Murry J, Turay D, Fam J, Oh JS, Gunter OL, Enniss T, Love JD, Skarupa D, Benns M, Fathalizadeh A, Leung PS, Carrick MM, Jewett B, Sakran J, O'Meara L, Herrera AV, Chen H, Scalea TM, Diaz JJ. Stapled versus hand-sewn: A prospective emergency surgery study. An American Association for the Surgery of Trauma multi-institutional study. J Trauma Acute Care Surg 2017;82:435-443.

28. Acosta S, Bjarnason T, Petersson U, Pålsson B, Wanhainen A, Svensson M, Djavani K, Björck M. Multicentre prospective study of fascial closure rate after open abdomen with vacuum and meshmediated fascial traction. Br J Surg 2011;98:735-743.

29. Nakagawa Y, Kobayashi K, Kuwabara S, Shibuya H, Nishimaki T. Use of indocyanine green fluorescence imaging to determine the area of bowel resection in non-occlusive mesenteric ischemia: A case report. Int J Surg Case Rep 2018;51:352-357.

30. Irie T, Matsutani T, Hagiwara N, Nomura T, Fujita I, Kanazawa Y, Kakinuma D, Uchida E. Successful treatment of non-occlusive mesenteric ischemia with indocyanine green fluorescence and openabdomen management. Clin J Gastroenterol 2017;10:514-518.

31. Weiss G, Lippert H, Meyer F. Successful management of nonocclusive mesenteric ischemia (NOMI) - case report. Pol Przegl Chir 2012;84:214-218.

32. Sommer CM, Radeleff BA. A novel approach for percutaneous treatment of massive nonocclusive mesenteric ischemia: tolazoline and glycerol trinitrate as effective local vasodilators. Catheter Cardiovasc Interv 2009;73:152-155.

Publisher's Note Springer Nature remains neutral with regard to jurisdictional claims in published maps and institutional affiliations. 


\section{Affiliations}

\section{Akira Endo $^{1}$ (D) $\cdot$ Fumitaka Saida $^{2} \cdot$ Yuzuru Mochida $^{3} \cdot$ Shiei Kim $^{4} \cdot$ Yasuhiro Otomo $^{1} \cdot$ Daisuke Nemoto $^{5}$. Hisahiro Matsubara ${ }^{6} \cdot$ Shigeru Yamagishi $^{7} \cdot$ Yoshinori Murao $^{8} \cdot$ Kazuki Mashiko $^{9} \cdot$ Satoshi Hirano $^{10}$. $^{1}$ Kentaro Yoshikawa ${ }^{11} \cdot$ Toshiki Sera $^{12} \cdot$ Mototaka Inaba $^{13} \cdot$ Hiroyuki Koami $^{14} \cdot$ Makoto Kobayashi $^{15} \cdot$ Kiyoshi Murata $^{16}$. Tomohisa Shoko ${ }^{2} \cdot$ Noriaki Takiguchi $^{17}$}

1 Trauma and Acute Critical Care Center, Tokyo Medical and Dental University Hospital of Medicine, 1-5-45 Yushima, Bunkyo-ku, Tokyo 113-8510, Japan

2 Emergency and Critical Care Medicine, Tokyo Women's Medical University Medical Center East, 2-1-10 Nishiogu, Arakawa-ku, Tokyo, Japan

3 Department of Trauma and Emergency Surgery, Saiseikai Yokohamashi Tobu Hospital, 3-6-1 Shimosueyoshi Tsurumi-ku, Yokohama, Kanagawa, Japan

4 Department of Emergency and Critical Care Medicine, Nippon Medical School, 1-1-5 Sendagi, Bunkyo-ku, Tokyo, Japan

5 Senshu Trauma and Critical Care Center, Rinku General Medical Center, 2-23 Rinku Ourai Kita, Izumisano, Osaka, Japan

6 Department of Frontier Surgery, Graduate School of Medicine, Chiba University, 1-8-1 Inohana, Chuo-ku, Chiba, Chiba, Japan

7 Department of Surgery, Fujisawa Municipal Hospital, 2-6-1, Fujisawa, Kanagawa, Japan

8 Department of Emergency and Critical Care Medicine, Kindai University Faculty of Medicine, 377-2 Ohnohigashi, Osakasayama, Osaka, Japan
9 Shock and Trauma Center, Nippon Medical School Chiba Hokusoh Hospital, 1715 Kamagari, Inzai, Chiba, Japan

10 Department of Gastroenterological Surgery II, Division of Surgery, Graduate School of Medicine, Hokkaido University, Kita14, Nishi5, Kita-Ku, Sapporo, Hokkaido, Japan

11 Department of General Surgery, Tokyo Bay Urayasu Ichikawa Medical Center, 3-4-32 Todaijima, Urayasu, Chiba, Japan

12 Critical Care Medical Center, Hiroshima Prefectural Hospital, 1-554 Ujinakanda, Minami-ku, Hiroshima, Japan

13 Department of Emergency Medicine, Okayama Saiseikai General Hospital, 2-25 Kokutaicho, Kita-ku, Okayama, Japan

14 Department of Emergency and Critical Cere Medicine, Saga University Faculty of Medicine, 5-1-1 Nabeshima, Saga, Japan

15 Tajima Emergency and Critical Care Medical Center, Toyooka Public Hospital, 1094 Tobera, Toyooka, Hyogo, Japan

16 Department of Emergency Medicine and Acute Care Surgery, Matsudo City General Hospital, 993-1 Sendabori, Matsudo, Chiba, Japan

17 Department of Surgery, Tsuchiura Kyodo General Hospital, 4-1-1 Otsuno, Tsuchiura, Ibaraki, Japan 